$16^{\text {th }}$ International Conference on

AEROSPACE SCIENCES \& AVIATION TECHNOLOGY,

$\boldsymbol{A S A T}$ - 16 - May 26 - 28, 2015, E-Mail: asat@mtc.edu.eg

Military Technical College, Kobry Elkobbah, Cairo, Egypt

Tel : +(202) 24025292-24036138, Fax: +(202) 22621908

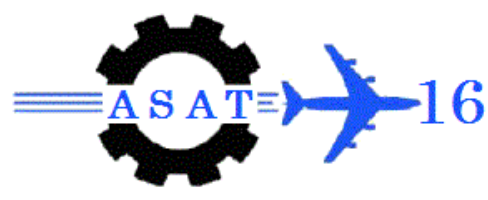

\title{
Preparation and Characterization of Electrically Switched Ion Exchange Films
}

\author{
Tawfic.A.F. ${ }^{*}$, Dickson.S.E. ${ }^{1}$, Kim.Y. ${ }^{1}$, Mekky.W. ${ }^{2}$ \\ 1-Department of Civil Engineering, McMaster University, 1280 Main St. West, L8S 4L8, \\ Hamilton, ON, Canada \\ 2-AMEC NSS, Power and Process America
}

\begin{abstract}
Wastewater treatment by conventional methods as ion exchange, coagulation and precipitation is very important. A relatively new method for wastewater treatment is introduced; this method is known as electrically switched ion exchange (ESIX). ESIX can be used to separate metal ion contaminants from industrial wastewater. The ESIX method involves sequential application of reduction and oxidation potentials to an ion exchange film to induce the respective loading and unloading of $\mathrm{Cs}^{+}$. The metal ion separated from the wastewater and unloaded from the electrode by modulating the potential applied to the film. This technology is superior to conventional methods (e.g conventional ion exchange) as it requires very little energy for ionic separation. In this study, two films of nickel hexacyanoferrate were prepared on nickel electrodes with different preparation procedures. Each film shows different performance in $\mathrm{Cs}^{+}$separation. Scanning electron microscopy was used to characterize the modified film surfaces. Cyclic voltammetry was used to investigate the ion exchange capacity and stability. These two films show a high capacity and stability for $\mathrm{Cs}^{+}$separation.
\end{abstract}

Keywords: Electrically switched ion exchange (ESIX), Nickel, ion separation, selectivity to cesium, nickel hexacyanoferrate, electroactive films. 


\section{Introduction:}

Cesium ion $\left(\mathrm{Cs}^{+}\right)$in radioactive waste is of particular concern as it is of high radioactivity and its half life time is almost 30 years $[1,2] . \mathrm{Cs}^{+}$separation from the radioactive fission products is of great importance, as its removal reduces the waste radioactivity. Recovered radioactive cesium can then be repurposed as a radioactive source for gamma irradiation in nuclear research facilities or used in medical equipment sterilization [3-6].

Electrically switched ion exchange (ESIX) combines the ion exchange process with electrode reactions for a reversible and selective separation of $\mathrm{Cs}^{+}$, and has the added benefit of generating relatively small amounts of secondary wastes [7]. The ESIX process was noticed to be selective to $\mathrm{Cs}^{+}$and $\mathrm{K}^{+}$than $\mathrm{Na}^{+}$. Further, the ESIX process is highly energy efficient, with small voltages required $(<2 \mathrm{~V})$ for the uptake and elution of ions [8].

The ESIX system consists of an electroactive ion exchange film that is electrochemically deposited onto a nickel electrode (Figure 1). The deposition of the ion exchange film is regulated using applied electric potential [9-12].

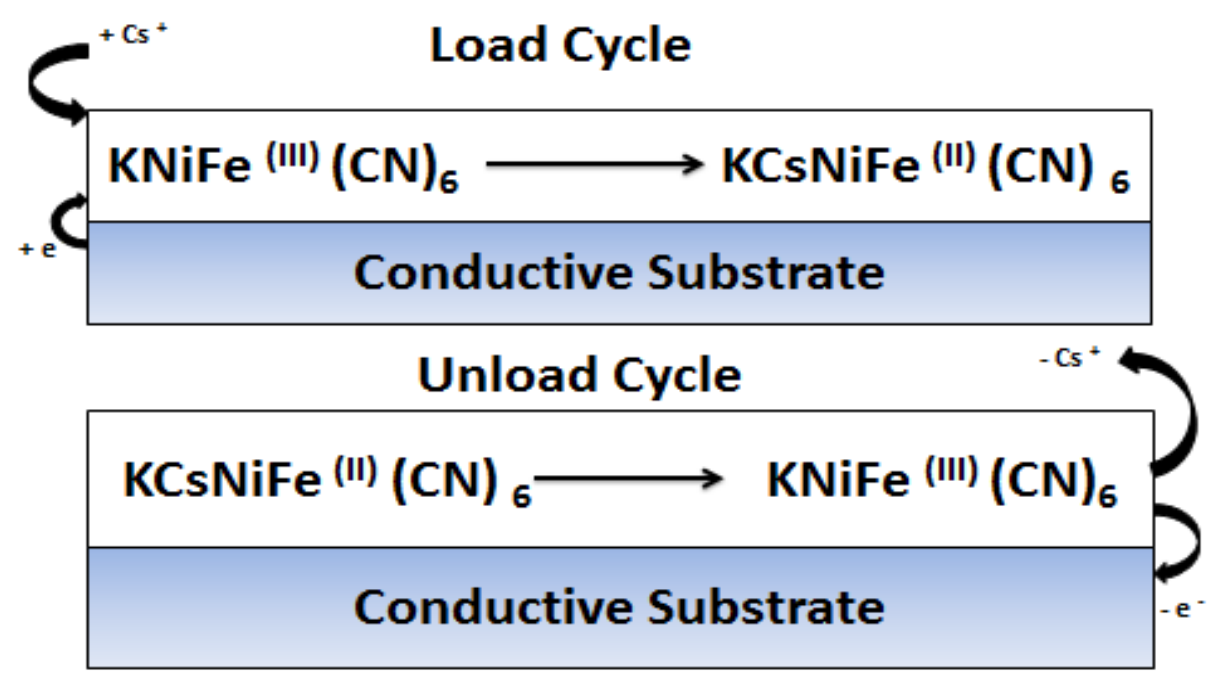

Figure (1) conductive substrate covered with Nickel hexacyanoferrate film [7].

Nickel electrode is subjected to an applied potential in a solution containing $\mathrm{K}_{3} \mathrm{Fe}(\mathrm{CN})_{6}$, the nickel on the surface is oxidized to $\mathrm{Ni}^{2+}$ on the electrode surface and reacts with the $\mathrm{Fe}(\mathrm{CN})_{6}$ anion in solution, causing the formation and precipitation of insoluble nickel hexacyanoferrate on the exposed portion of the electrode. The reaction is shown in equation 1 [8].

$$
\mathrm{Ni}^{+2}+\mathrm{K}_{3} \mathrm{Fe}(\mathrm{CN})_{6}
$$$$
\mathrm{KNiFe}(\mathrm{CN})_{6}+2 \mathrm{~K}^{+}+2 \mathrm{e}^{-}
$$ 
The reduction of the ferricyanide film requires the uptake of $\mathrm{Cs}^{+}$from waste solution. While the oxidation requires a release of the same ion back into concentration solution in order to maintain electro neutrality of the film, the oxidation of ferrocyanide film to the ferricyanide form, equation 2, and the reduction of the ferricyanide film to the ferrocyanide form, equation 3 , are the main driving forces behind the ion exchange $[9,13]$.

$$
\begin{aligned}
& \mathrm{CsKNiFe}^{\mathrm{II}}(\mathrm{CN})_{6} \rightarrow \mathrm{KNiFe}^{\mathrm{III}}(\mathrm{CN})_{6}+\mathrm{Cs}^{+}+\mathrm{e}^{-} \\
& \mathrm{KNiFe}^{\mathrm{III}}(\mathrm{CN})_{6}+\mathrm{Cs}^{+}+\mathrm{e}^{-} \rightarrow \mathrm{CsKNiFe}^{\mathrm{II}}(\mathrm{CN})_{6}
\end{aligned}
$$

\section{Experimental methods}

\subsection{General and electrochemical}

A Potentiostat (Wave Driver 10, Pine Research Instrumentation) was used to deposit and characterize films. The software that was used to control the Potentiostat (Aftermath 2.0) was provided by Pine Research Instrumentation. A standard three-electrode system was used in the preparation and characterization of electroactive films. A saturated calomel electrode (SCE) was used as a reference electrode for the potential measurements. A platinum counter electrode with a surface area of $5 \mathrm{~cm}^{2}$ was employed in all experiments. The reference and the counter electrode were located less than two $\mathrm{cm}$ from the working electrode. The working electrode was composed of nickel and its composition and preparation is further described in Section 2.2.

The chemicals which were used, $\mathrm{K}_{3} \mathrm{Fe}(\mathrm{CN})_{6}, \mathrm{KNO}_{3}$, and $\mathrm{CsNO}_{3}$, were all reagent-grade with greater than $99 \%$ purity and were used without further purification. Deionized water (18.2 $\mathrm{M} \Omega \mathrm{cm}^{-1}$ ) was used in all salt solution preparations and cleaning of electrochemical cell components.

\subsection{Surface preparation}

Nickel disks (99.99\% pure) were used as the working electrodes. A nickel disk was embedded in a Teflon holder suspended in the test solution. The portion of the disk exposed to test solution has a diameter of $0.5 \mathrm{~cm}$ and an area $0.2 \mathrm{~cm}^{2}$.

\subsection{Film preparation}

The nickel hexacyanoferrate films preparation methodology was adapted from the method described by Bocarsly et al. [14, 15] In their work, nickel was first oxidized at an anodic potential of $0.6 \mathrm{~V}-1 \mathrm{~V}$ relative to SCE for approximately $30 \mathrm{~min}$. in a solution containing 10 $\mathrm{mM} \mathrm{M} \mathrm{M}_{3} \mathrm{Fe}(\mathrm{CN})_{6}$ and a supporting electrolyte $0.1 \mathrm{M} \mathrm{MNO}_{3}$, and an insoluble, stable alkali $\mathrm{MNiFe}^{\mathrm{III}}(\mathrm{CN})_{6}$ was formed on the electrode surface, where $\mathrm{M}$ was $\mathrm{K}, \mathrm{Na}$, or Cs. 
In this work, a solution containing $30 \mathrm{mM} \mathrm{K} 3 \mathrm{Fe}(\mathrm{CN})_{6}$ and $0.5 \mathrm{M} \mathrm{KNO}_{3}$ was used for the film preparation. The solution had oxygen stripped from it by bubbling nitrogen gas through the solution before starting the deposition procedure. Table 1 represents the different parameters for film preparation.

Table 1: film preparation voltage

\begin{tabular}{|c|c|c|}
\hline Film number & $\mathbf{1}^{\text {st }} \mathbf{s t e p}(\mathbf{2 0} \mathbf{~ m i n})$ & $\mathbf{2}^{\text {nd }} \mathbf{s t e p}(\mathbf{2 0} \mathbf{~ m i n})$ \\
\hline $\mathrm{A}$ & $0.25 \mathrm{~V}$ & $1.1 \mathrm{~V}$ \\
\hline $\mathrm{B}$ & $0.3 \mathrm{~V}$ & $1.15 \mathrm{~V}$ \\
\hline
\end{tabular}

Two ESIX films were prepared by submerging a nickel electrode in a solution of $30 \mathrm{mM}$ $\mathrm{K}_{3} \mathrm{Fe}(\mathrm{CN})_{6}$ and $0.5 \mathrm{M} \mathrm{KNO}_{3}$ and then applying the electrical potential for the initial phase of the film deposition. For film (A) a potential of $0.25 \mathrm{~V}$ was applied for 20 minutes and then a potential of $1.1 \mathrm{~V}$ was applied for a further 20 minutes. While in film (B) a potential of $0.3 \mathrm{~V}$ was applied for 20 minutes and then a potential of $1.15 \mathrm{~V}$ for further 20 minutes was applied. The purpose of using low voltage for the first step was to form a very thin mononuclear layer on the ESIX film to act as a nucleation sites for the other layers of the ESIX film, which were deposited under the higher voltage in the second step.

\subsection{Film characterization}

The film was characterized in multiple ways. First, the surface morphology for the prepared films was imaged using scanning electron microscopy conducted using a JOEL 7000 electron microscope to examine the film morphology.

The film's capability for repeated cycling of ESIX was characterized using cyclic voltammetry, which was conducted in a $1 \mathrm{M} \mathrm{CsNO}_{3}$ solution. The applied potential started at $0.2 \mathrm{~V}$ and was scanned anodically to $0.9 \mathrm{~V}$ then catholically to $-0.2 \mathrm{~V}$ then back to $0.2 \mathrm{~V}$ at a scan rate of $100 \mathrm{mV} \mathrm{s}^{-1}$.

\section{Results and discussion}

\subsection{Film morphology by SEM}

Figure 2 is the SEM image of the two films. The surface of the nickel electrode coated with hexacyanoferrate is displayed at a magnification of 30,000 X. 


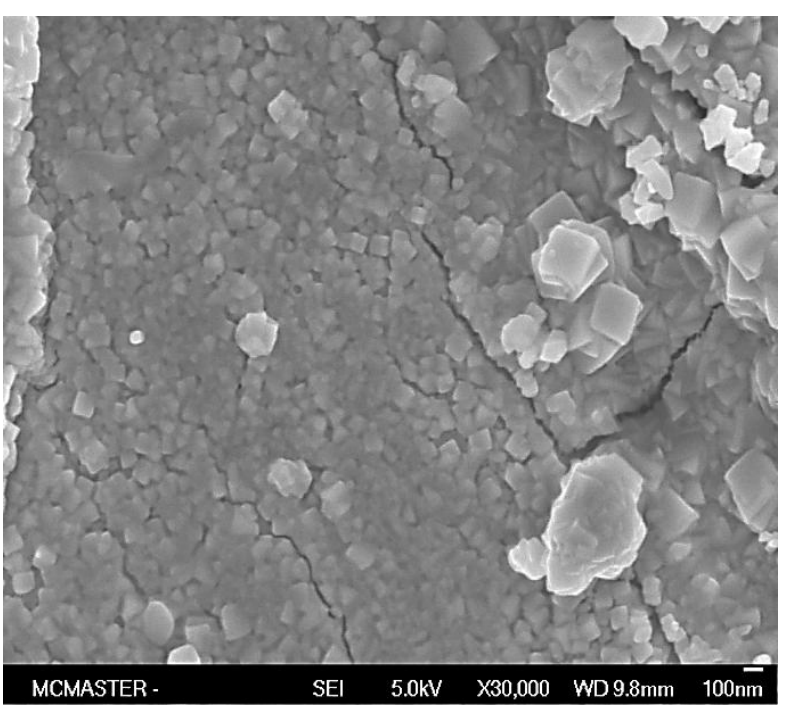

Film (A)

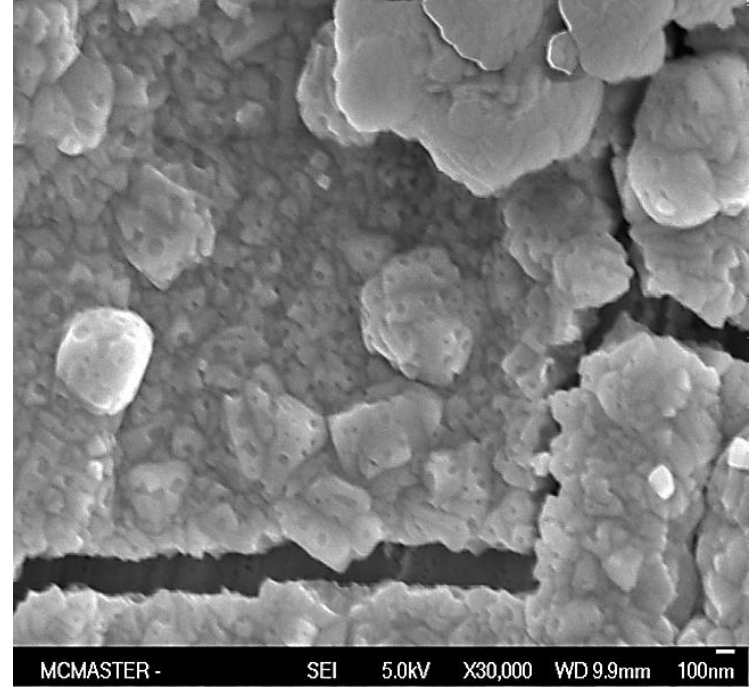

Film (B)

Figure 2: SEM images of the two films

Film (A) image shows a uniform layer of the prepared film. However this film seems to be more uniform than film (B) with few cracks. These cracks are believed to be happened due to the drying process before SEM imaging. We believe that these cracks don't exist in the film used to load and unload $\mathrm{Cs}^{+}$. This uniform layer is believed to be formed due to the initial low applied voltage in the first step $(0.25 \mathrm{~V})$ followed by the $2^{\text {nd }}$ step $(1.1 \mathrm{~V})$.

The image of Film (B) shows a denser layer of the prepared film than Film (A). However it have one big crack which is also believed to happened due to the drying process before SEM imaging, also it shows that the surface of the film is full of pitting. The $1^{\text {st }}$ step applied potential $(0.3 \mathrm{~V})$ leads to the formation of a strong monolayer of nickel hexacyanoferrate while The higher voltage for the $2^{\text {nd }}$ step in the film preparation $(1.15 \mathrm{~V})$ causes more layers of nickel hexacyanoferrate to be built up, forming this more densely layered film and leads to the formation of more pitting causing the increase of the film surface area.

\subsection{Film characterization (Cyclic Voltammogram)}

Voltammogram curves are shown for each film which represents the electrical behavior of the films for cycles 1 and 1000. From this measurement, it is possible to determine how the capacity diminishes during repetitive $\mathrm{Cs}^{+}$loading and unloading.

Also shown is the integration of the current signal obtained from the voltammogram. This was measured in order to calculate the maximum charge capacity of each film as well as its surface coverage. The maximum charge capacity is simply the total amount of charge that the film is able to retain per unit area, while the surface coverage is calculated by dividing the maximum charge capacity by Faraday's Constant to obtain the number of redox species that 
contribute to the current. These calculations give insight to the number of active site per unit area [16].

\subsubsection{Film A (0.25 V then 1.1 V)}

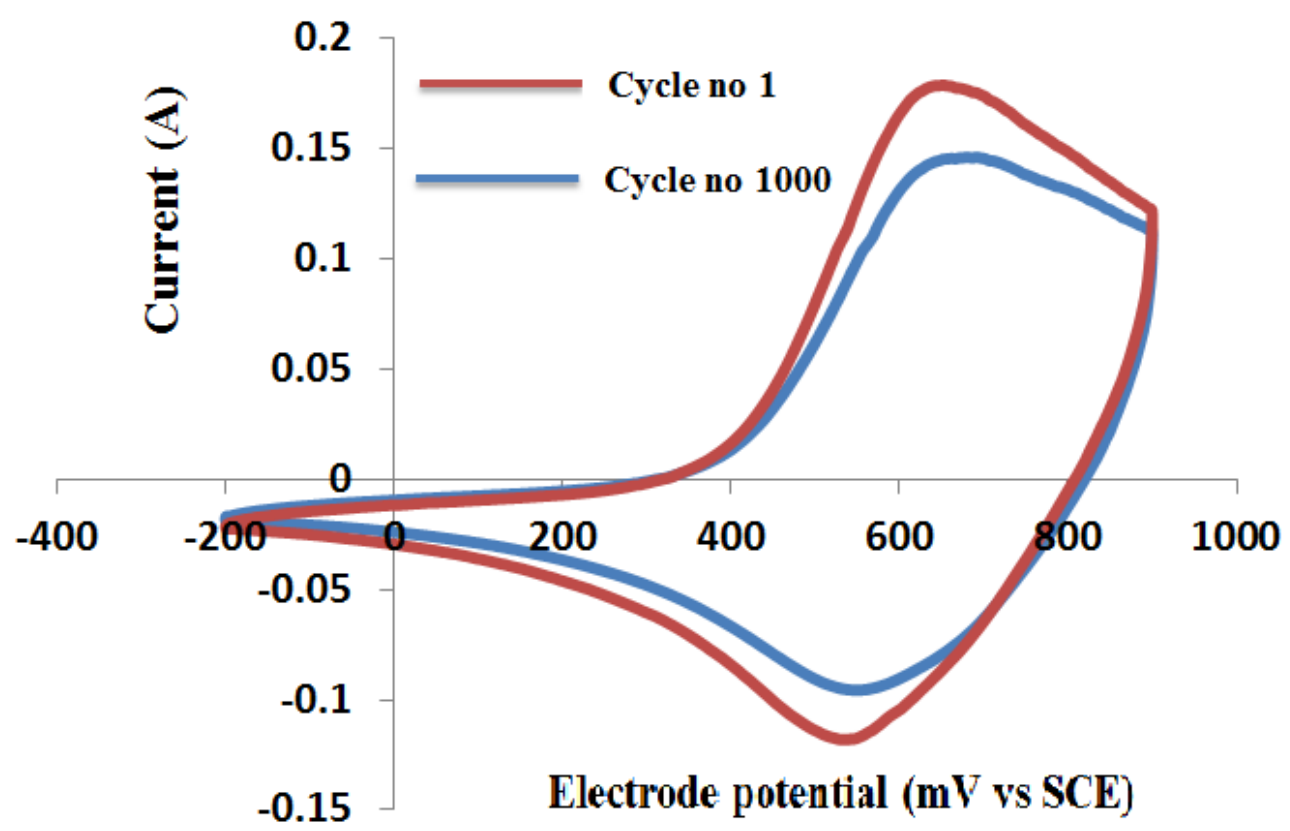

Figure 3: Cyclic voltammogram for Film $\mathrm{A}$ in $1 \mathrm{M} \mathrm{CsNO}_{3}$

Figure (3) shows the cyclic voltammogram for Film A in a $1 \mathrm{M} \mathrm{CsNO}_{3}$ solution. The shape of the cyclic voltammogram in the figure confirms that the loading and unloading of $\mathrm{Cs}^{+}$is occurring. The curves represent the voltammogram for cycles 1 and 1000. The peak current during the reduction cycle occurred at an applied potential of approximately $570 \mathrm{mV}$, where $\mathrm{Cs}^{+}$was loaded and the current approached $0 \mathrm{~mA}$ at $300 \mathrm{mV}$ as the reduction of ferricyanide to ferrocyanide neared completion and terminated the uptake of $\mathrm{Cs}^{+}$. The oxidation of ferrocyanide to ferricyanide begins with the unloading of $\mathrm{Cs}^{+}$from the film, which occurred at $800 \mathrm{mV}$, and the peak current during the release of $\mathrm{Cs}^{+}$from the cyclic voltammogram occurred at $650 \mathrm{mV}$. The peak current was reduced in cycle 1000, which indicates that the film loses its capacity during the $\mathrm{Cs}^{+}$removal process. The film capacity was reduced by approximately $35 \%$ after 1000 cycles of loading and unloading $\mathrm{Cs}^{+}$. 


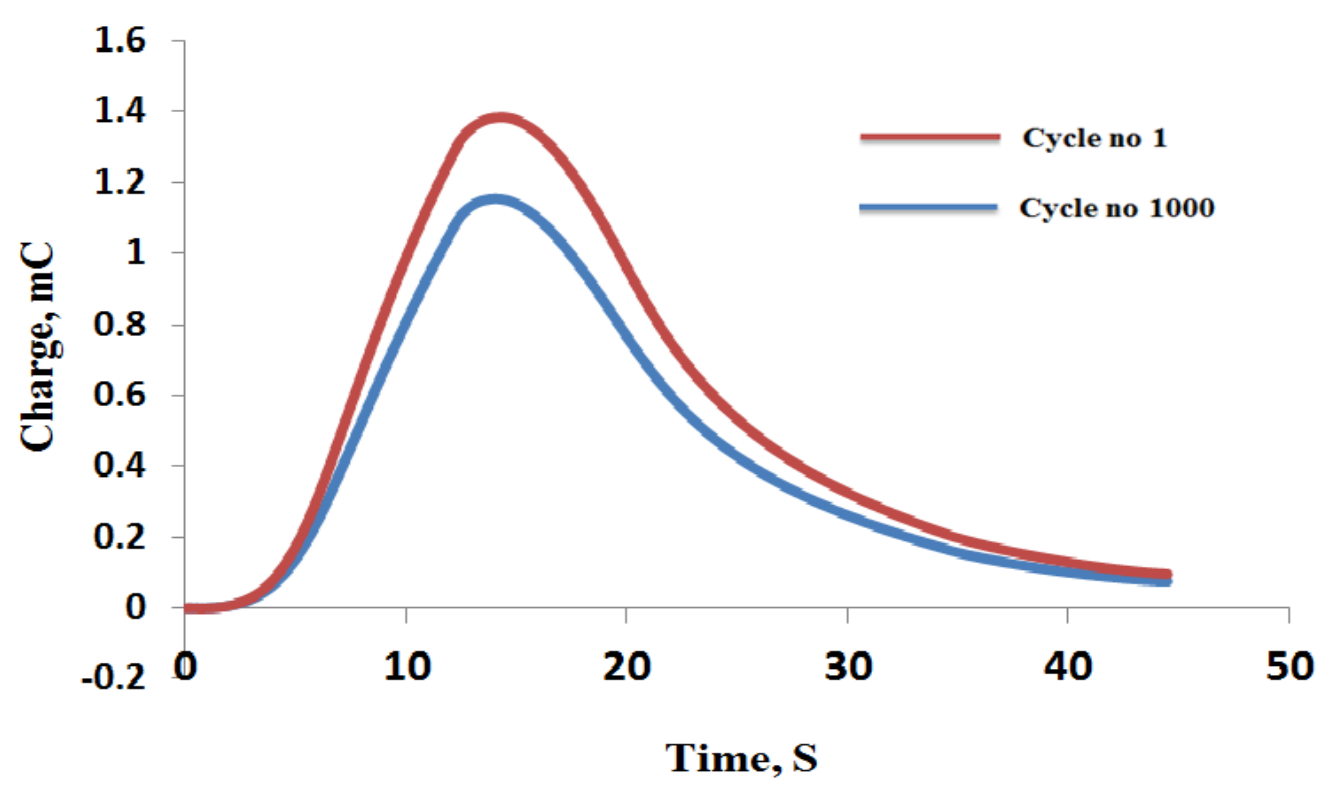

Figure 4: Integration of the current over the $1^{\text {st }}$ and $1000^{\text {th }}$ voltammetry sweeps for Film A Figure 4 shows the capacity of Film A by integrating the current over the course of cycles 1 and 1000 from the voltammetry sweeps with respect to time. The maximum charge capacity of the film at cycles 1 and 1000 is summarized in Table 3.

Table 3: Film A characterization after cycles 1 and 1000

\begin{tabular}{|c|c|c|}
\hline Cycles & Maximum charge capacity & Surface coverage \\
\hline 1 & $12 \times 10^{-3} \mathrm{C} \mathrm{cm}^{-2}$ & $1.2 \times 10^{-7} \mathrm{~mol} \mathrm{~cm}^{-2}$ \\
\hline 1000 & $7.5 \times 10^{-3} \mathrm{C} \mathrm{cm}^{-2}$ & $7 \times 10^{-8} \mathrm{~mol} \mathrm{~cm}^{-2}$ \\
\hline
\end{tabular}

\subsubsection{Film B (0.3 V then $1.15 \mathrm{~V})$}

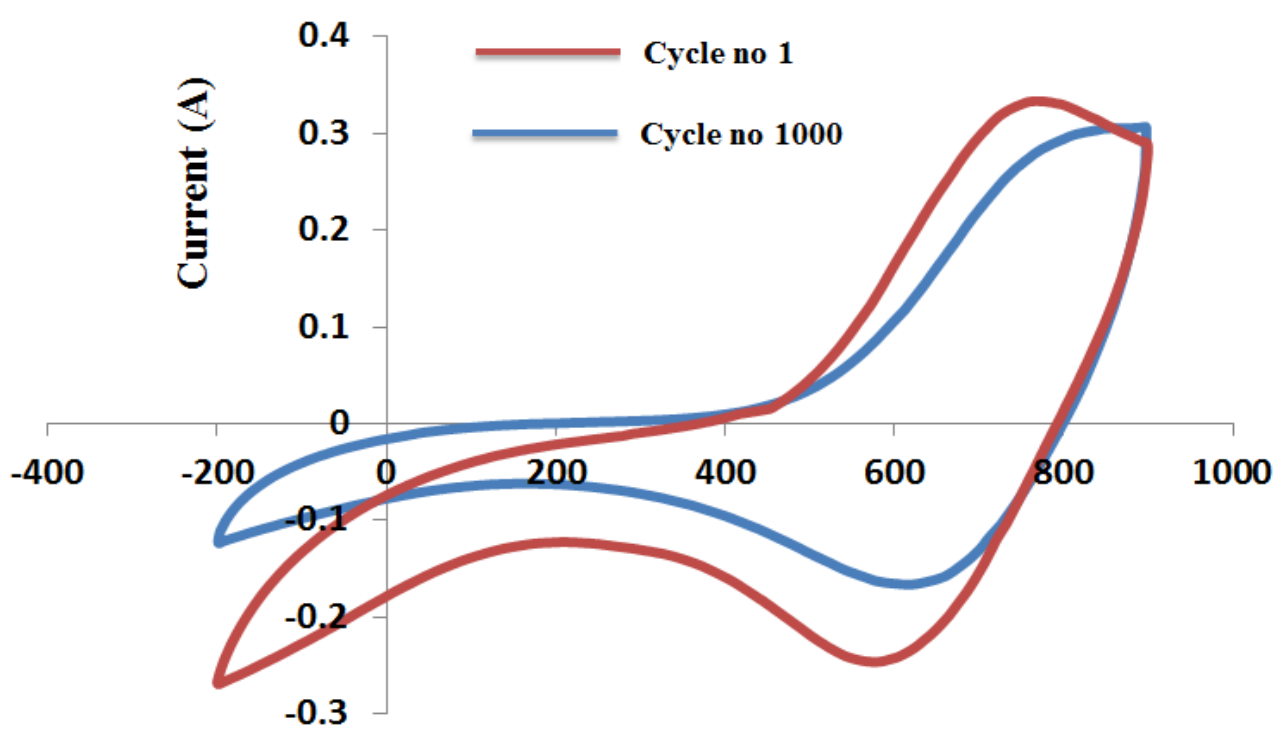

Electrode potential ( $\mathrm{mV}$ vs SCE)

Figure 5: Cyclic voltammogram for Film $\mathrm{B}$ in $1 \mathrm{M} \mathrm{CsNO}_{3}$ 
Figure 5 shows the behavior of Film B under cyclic voltammetry in a $1 \mathrm{M} \mathrm{CsNO}_{3}$ solution. During $\mathrm{Cs}^{+}$loading, the peak current occurred at an applied potential of approximately 600 $\mathrm{mV}$, and the current approached zero at $350 \mathrm{mV}$ as the maximum amount of $\mathrm{Cs}^{+}$was removed from solution. The oxidation of ferrocyanide to ferricyanide occurs as $\mathrm{Cs}^{+}$is unloaded, and the peak current achieved was $750 \mathrm{mV}$. There was a $10 \%$ decrease in the peak current between cycle 1 and cycle 1000.

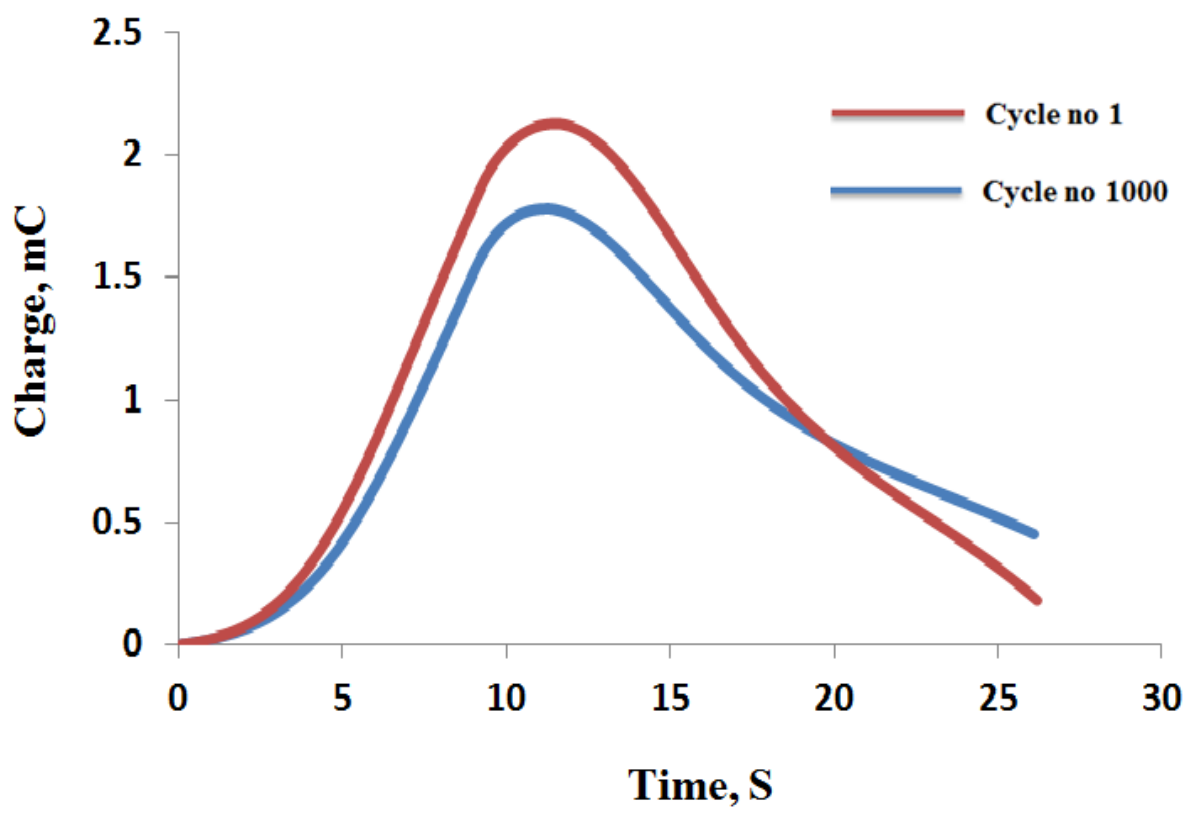

Figure 6: Integration of the current from cycles (1 and 1000) of Film B.

Figure 6 shows the capacity of the film. The maximum charge capacity of the film at cycles 1 , and 1000 is summarized in table 4 .

Table 4: Film B characterization after cycles 1, 500 and 1000.

\begin{tabular}{|c|c|c|}
\hline Cycles & Maximum charge capacity & Surface coverage \\
\hline 1 & $13 \times 10^{-3} \mathrm{C} \mathrm{cm}^{-2}$ & $1.23 \times 10^{-7} \mathrm{~mol} \mathrm{~cm}^{-2}$ \\
\hline 1000 & $10.2 \times 10^{-3} \mathrm{C} \mathrm{cm}^{-2}$ & $9.8 \times 10^{-8} \mathrm{~mol} \mathrm{~cm}^{-2}$ \\
\hline
\end{tabular}

\section{Conclusion}

Two hexacyanoferrate films were prepared on nickel electrodes using different applied potentials in order to examine their capability for the electronically switched ion exchange of the $\mathrm{Cs}^{+}$ion from an aqueous solution. These films were compared by examining the surface morphology using SEM and their performance through cyclic voltammetry. The results show that there is a significant difference in the performance of the prepared films with regard to 
$\mathrm{Cs}^{+}$loading and unloading, and that each film performance depends on the applied potentials used during the preparation of the film. In this instance, a film which was prepared by depositing nickel hexacyanoferrate using an initial voltage of $0.3 \mathrm{~V}$ relative to a SCE for 20 minutes in the initiation stage, followed by a voltage of $1.15 \mathrm{~V}$ relative to SCE for 20 minutes for film growth, demonstrates the best performance, as it demonstrated the lowest reduction in capacity with repeated cycling; which gives evidence that it would be a good candidate for electrically switched ion exchange film for the removal of $\mathrm{Cs}^{+}$from solution.

\section{Acknowledgements}

The authors would like to thank the Egyptian Ministry of Defense (EMD) and the Natural Science and Engineering Research Council of Canada (NSERC) (Discovery Grants Program) for supporting this work.

\section{References}

[1] Arthur S., Kubo and David J. Rose. (1973) "Disposal of Nuclear Wastes" Volume 182, PP 4118.

[2] Rayford, G. and Anthony, Robert G. (1994) "Use of Silicotitanates for Removing Cesium and Strontium from Defense Waste" Ind. Eng. Chem. Res, 33, PP 2702-2705.

[3] Bhaskar N. D., and Khla, C. M. (1990) “Adsorption of cesium by polycrystalline graphitesticking coefficient studies" Carbon Vol. 2 pp. 71-78.

[4] Herbst R. S. and Law, J. D. (2007) "Development and testing of a cobalt dicarbollide based solvent extraction process for the separation of cesium and strontium from acidic tank waste" Separation Science and Technology

[5] Mohapatra, P. K., Lakshmi, D. S., Bhattacharyya, A., and Manchanda, V. K. (2009)"Evaluation of polymer inclusion membranes containing crown ethers for selective cesium separation from nuclear waste solution" Journal of Hazardous Materials, 169, PP 472-490.

[6] Mohapatra, P. K., Bhattacharyya, A., and Manchanda, V. K. (2010) "Selective separation of radio-cesium from acidic solutions using supported liquid membrane containing chlorinated cobalt dicarbollide (CCD) in phenyl trifluoromethyl sulphone (PTMS)." Journal of Hazardous Materials, 181, PP 679-85.

[7] Tawfic, A. F.; Dickson, S.; Younggy, K.; Mekky, W; "Enhanced capacity and stability for the separation of cesium in electrically switched ion exchange" Fusion Science and Technology, Vol 67 , no 3 , April 2015 ,Pages 608-611. 
[8] Rassat, S.D., Sukamto, J.H., and Lilga, M.A. (1999) "Development of an electrically switched ion exchange process for selective ion separations" Separation and ectroamai. Chem., 210, PP 323-328.

[9] Lilga M.A., Orth, R.J., Sukamto, J.P.H., Haight, S.M., and Schwartz, D.T. (1997) "Metal ion separations using electrically switched ion exchange" Separation and Purification Technology 11, PP 147-158.

[10] XiaogangHao, YongguoLi , Mark Pritzker "Pulsed electrodeposition of nickel

Hexacyanoferrate films for electrochemically switched ion exchange" Separation and Purification Technology 63 (2008) 407-414.

[11] Marceline N. Akieh, Stephen F. Ralph, Johan Bobacka, Ari Ivaska" Transport of metal ions across an electrically switchable cation exchange membrane based on polypyrrole doped with a sulfonated calixarene” Journal of Membrane Science 354 (2010) 162-170

[12] Inamuddin ,Yahya A. Ismail" Synthesis and characterization of electrically conducting poly-o-methoxyaniline $\mathrm{Zr}(1 \mathrm{~V})$ molybdate $\mathrm{Cd}(\mathrm{II})$ selective composite cation-exchanger" Desalination 250 (2010) 523-529

[13] Lilga, M.A., Orth, R.J., Sukamto, J.P.H., and Rassat, S.D. (2001) "Cesium separation using electrically switched ion exchange” Separation and Purification Technology 24, PP 451-466.

[14] A.B. Bocarsly, S. Sinha, Chemically derivatized nickel surfaces: synthesis of a new class of stable electrode interfaces, J. Electroanal. Chem. 137 (1982) 157.

[15] A.B. Bocarsly, S. Sinha, Effects of surface structure on electrode charge transfer properties. Induction of ion selectivity at the chemically derivatized interface, J. Electroanal. Chem. 140 (1982) 16

[16] Prodromidis, M. I., Florou, A. B., Tzouwara-Karayanni, S. M., and Karayannis, M. I.(2000), "The Importance of Surface Coverage in the Electrochemical Study of Chemically Modified Electrodes” Electroanalysis PP 1498-1501. 